\title{
What is the impact of flexicurity on the chances of entry into employment for people with low education and activity limitations due to health problems? A comparison of 21 European countries using Qualitative Comparative Analysis (QCA)
}

\author{
Mona C Backhans ${ }^{1,2^{*}}$ (D), Sarah Mosedale ${ }^{3}$, Daniel Bruce ${ }^{1,2}$, Margaret Whitehead ${ }^{4}$ and Bo Burström ${ }^{1,2}$
}

\begin{abstract}
Background: Employment and unemployment are key determinants of health inequalities and should be a priority when discussing policies to reduce such inequalities. Our aim is to investigate how flexicurity policies across European countries impact on the employment chances for people with low education and activity limitations.

Methods: The longitudinal EU-SILC dataset, pooled 2005-2010, was used to calculate labour market outcomes. The sample consisted of 25 countries and 19,881 individuals. The employment transitions of non-employed people with activity limitations was followed from one year to the next, and the outcomes were rates of return-to work (RTW) among those with low education, and relative equality of RTW between those with low and high education (rate ratio, RR).

Data on flexicurity policy and labour market factors were accessed from Eurostat and the OECD. As policy data was only available for OECD countries, the sample was reduced to 21 countries. Fuzzy-set QCA (Qualitative Comparative Analysis) was used to examine how different combinations of the components of flexicurity were linked to the two outcomes.

Results: Where high rates of RTW were achieved, high employment rates were always present. In five countries (the Nordic countries and the Netherlands) these factors coexisted with high expenditure on active labour market policies and social services in old age. In three others (The Czech Republic, UK and Estonia) they were combined with low employment protection and low benefit expenditure. For equality in RTW, low unemployment rates were combined with either high benefit expenditure, or low employment protection.

(Continued on next page)
\end{abstract}

\footnotetext{
* Correspondence: Mona.backhans@ki.se

${ }^{1}$ Department of Public Health Sciences, Karolinska Institutet, Stockholm,

Sweden

${ }^{2}$ Centre for Epidemiology and Community Health, Stockholm County

Council, Stockholm, Sweden

Full list of author information is available at the end of the article
} 
(Continued from previous page)

Conclusion: We found two routes that lead to high RTW: we characterise these as the high road and the low road. Taking the low road (relaxing employment protection and limiting benefits) may be a tempting option for poorly performing countries. However, without measures to stimulate female employment it may not be enough as high overall employment is so important in enabling people with activity limitations to access the labour market. To achieve equality in RTW, it seems that as long as unemployment is low, either flexibility or security is sufficient.

Keywords: Flexicurity, Employment, Activity limitations, Inequalities, QCA, EU-silc

\section{Background}

Employment is a key determinant of both health and health inequalities and should be a priority when discussing policies to reduce such inequalities in the wake of the recession. How activity limitations due to health problems impacts differently on people's employment depending on their socioeconomic status constitutes a critical field of research for understanding and reducing health inequalities [1]. Research suggests that greater investments in active labor market policies (ALMP) directed at the unemployed or employers, such as training and wage subsidies, can improve the chances of people with activity limitations finding employment [2]. However, a review of return-to-work interventions concluded that, although workplace adjustments and involving employers in return-to-work planning did impact positively on employment, both interventions suffered from low uptake [3]. Finding that financial incentives such as wage subsidies could be efficient if sufficiently generous, the authors emphasised the need to pay more attention to the differential impact of such interventions [3].

This study analyses the effects of flexicurity, which the European Commission [4] describes as "about striking the right balance between flexible job arrangements and secure transitions between jobs so that more and better jobs can be created. The idea is that flexibility and security should not be seen as opposites but as complementary." Flexicurity is a politically mandated goal in the EU, and since there is a large variation between different states, it is suitable for comparative analysis. Conceptions of flexicurity range from Sperber's simple model [5], where flexibility and security are represented by employment regulation and unemployment benefits, to the elaborate multidimensional models used by the European Commission [6, 7] and the European Foundation [8]. The European Commission suggest four core dimensions of flexicurity: flexible and reliable contractual arrangements; comprehensive lifelong learning strategies; effective labour market policies; and modern social security systems (further divided into security systems and reconciliation of work and private life) [9].

Previous research using panel regression analyses for 20 EU countries between 1990 and 2008 showed that expenditure on active labour market policies (ALMP) was positively associated with high employment and low unemployment [10]. Another study using fuzzy-set QCA [11] for 18 OECD countries between 2001 and 2008 suggested that long-term unemployment was high in the presence of strict employment protection legislation (EPL) for temporary workers (rules for when fixed-term contracts can be used, and the maximum number and total duration of successive fixed-term contracts) in combination with a relatively high statutory minimum wage. On the other hand, a relatively low statutory minimum wage was shown to lead to high levels of nonstandard employment (part-time and temporary work), in combination with either strict EPL for permanent workers or weak EPL for temporary workers [12]. A multilevel study investigating ALMP, benefit generosity and employment protection found that the first two were associated with lower levels of, and lower inequalities in, unemployment among those reporting a limiting long-standing illness [13].

The outcome considered in this study is return-towork rates (rather than employment rates) among people with activity limitations (defined as "activity limitations due to health problems that have lasted more than six months") and low education. Our aim is to investigate how flexicurity policies across Europe impact on the employment chances for people in this group. They are especially vulnerable on the labour market, and their exclusion from it often serves to exacerbate their health problems. To address the equality dimension, we also looked at relative differences between those with high and low education. If people with low education are especially badly hit when experiencing health problems, this may be an important mechanism in explaining health inequalities.

Based on previous research, we now describe the hypothetical consequences of the European Commission's model of flexicurity $[4,9]$ for people with activity limitations and low education:

Flexible and reliable contractual arrangements: often operationalized as employment protection legislation for temporary and standard workers [4]. EPL concerns 
rules regarding hiring and firing, strictness of regulation of temporary contracts, and regulation of temporary agency work. Less strict EPL is likely to help outsiders enter the labour market $[14,15]$, but may on the other hand lead to 'insiders' losing their jobs if they become ill [16, 17].

Comprehensive lifelong learning strategies concern both regular education and continuing on-the-job training, and "require the active involvement of governments, social partners, enterprises, and individual workers" [4]. Life-long learning (LLL) complements ALMP (below) and could be seen as extending the strategy of skill enhancement to those in employment. It has been found that firm-provided training significantly increases future employment prospects and both current and future wages $[18,19]$. However we are interested in labour market outsiders, for whom LLL may be less important.

Effective labour market policies, defined as active labour market measures (ALMP) and public employment services (PES) [4]. ALMP includes training, employment subsidies, rehabilitation, direct job creation and the provision of wage subsidies to firms that employ people with disabilities. PES covers labour market interventions related to job-search activities. Both ALMP and PES should improve opportunities for employment, although different measures may not be equally efficient [20-22]. A recent evaluation of German ALMP shows that programme participation was equally beneficial regardless of education and skills level [23]. ALMP is expected to be associated with higher levels of return to work.

Modern social security systems; i.e. adequate income support that both encourages employment and facilitates labour market mobility [4]. Relatively high and long-lasting benefits can lead to longer periods of unemployment, by decreasing job search intensity and increasing workers' reservation wage [24, 25]. However, adequate unemployment benefits may improve the quality of job matches and increase wages [24]. Furthermore, benefit sanctions and warnings have been found to not only increase exit from unemployment, but also exit into non-employment, and to lower the quality of the jobs found both in terms of their duration and levels of pay [26]. Sickness benefits can be seen as an alternative to unemployment benefits for people with health problems. Studies show that the design of the benefit system strongly impacts on inflow and outflow into sickness and unemployment insurance $[27,28]$. However, people with long-term health problems may be less likely to be affected by benefit levels, given that they may be simply too ill to work [29]. We make no hypotheses regarding the direction of association for benefit expenditure, as this is likely to differ depending on the surrounding policy and labour market context.

Reconciliation of work and private life; made possible by high social services expenditure on child care [4]; in this study we have also included social services expenditure in old age. With population ageing, caring for elderly parents has become a concern for many people in midlife, and may impede opportunities for labour market participation. Social services are part of flexicurity in that they promote employment [30]. Such expenditure may be especially important for those on a low income as it is likely to lead to less expensive services. Given the gendered nature of caring, women in our target group probably benefit most from this [31].

In summary, our tentative hypothesis is that flexicurity, i.e. less strict EPL combined with high ALMP and LLL, high expenditure on social services and adequate social security benefits, will be more beneficial for return-to-work than either flexibility without security, or security without flexibility. This is in accordance with the expectation that flexicurity should combine 'the best of both worlds' i.e. high labour market transition rates and high social security while avoiding segmentation between labour market 'insiders' and 'outsiders'.

European countries are very dissimilar not only in terms of policy but also background characteristics such as the economic and labour market situation, and the overall impact of the recession. When discussing outcomes in terms of employment rates among people with activity limitations, it is important to bear this in mind. Of course policy also contributes to or impedes the functioning of the labour market to create virtuous or vicious circles.

\section{Methods}

\section{Outcome data - return to work rates and ratios}

The longitudinal EU-SILC dataset was used to calculate our outcome of interest i.e. return to work (RTW). We pooled data between 2005 and 2010 and included those EU countries that participated in the study throughout this period (so excluding Germany). Also included were Norway and Switzerland. Two countries (Bulgaria and Malta) were excluded because the number of individuals in certain subgroups was too small to allow a good model fit.

The employment transitions of people with activity limitations was followed from one year to the next in each country, comparing the likelihood of getting a job for those with low or high levels of education (Fig. 1). This was done in both absolute and relative terms where the absolute measure was percentage in employment at follow-up among those with low education (also referred to as return-to-work or RTW), and the relative measure was the rate ratio of RTW. 
Year 1

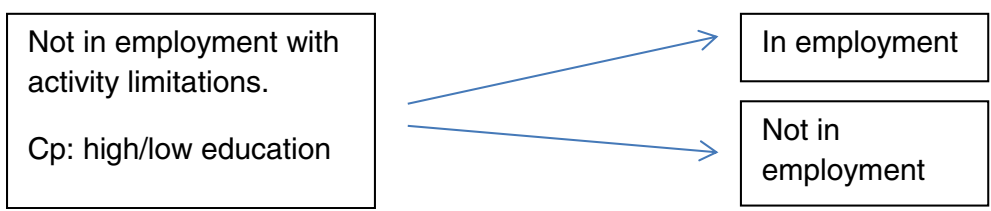

Fig. 1 Basic study design using EU-SILC data (2005-2010)

Year 1 is any year between 2005 and 2009 and Year 2 the one immediately following. Included at Year 1 are those aged 25-59 who reported that they were out of work and had activity limitations due to health problems which had lasted at least six months. Those who stated that they were permanently out of the labour force were excluded. This resulted in a sample of 25 countries and 19,881 individuals (see Table 1 in the results section for a list of included countries).

Table 1 Numbers included in analysis, number and percentage employed at Year 2

\begin{tabular}{lll}
\hline Country & $\mathrm{N}$ & Employed at T2 $\mathrm{n}(\%)$ \\
\hline AT & 690 & $95(14)$ \\
BE & 880 & $72(8)$ \\
CY & 593 & $63(11)$ \\
CZ & 706 & $166(24)$ \\
DK & 206 & $68(33)$ \\
EE & 625 & $162(26)$ \\
ES & 2350 & $316(13)$ \\
FI & 462 & $137(30)$ \\
FR & 1298 & $175(13)$ \\
GR & 532 & $52(10)$ \\
HU & 1138 & $229(20)$ \\
IE & 520 & $35(7)$ \\
IT & 2238 & $248(11)$ \\
LT & 437 & $95(22)$ \\
LU & 635 & $73(12)$ \\
LV & 810 & $203(25)$ \\
NL & 675 & $118(17)$ \\
NO & 205 & $71(35)$ \\
PL & 1512 & $194(13)$ \\
PT & 1144 & $147(13)$ \\
RO & $244(12)$ \\
SE & $584(34)$ \\
SI & $91(20)$ \\
SK & $155(21)$ \\
UK & & \\
\hline & 210 & $291)$ \\
\hline
\end{tabular}

The proportion of the study population classified as having only primary education varies from nil (the Czech Republic, Denmark) to 69 \% (Portugal). In order to compensate for this and to try to identify similar proportions of the national populations as having a relatively low level of education, we drew the line between low and middle educational attainment differently in different countries. It therefore varies between either primary and lower secondary, or between lower secondary and upper secondary. Despite this, the size of the group with low educational attainment varies from $15 \%$ (Sweden) to $84 \%$ (Portugal). Table 7 in Appendix 1 shows the educational distribution and chosen thresholds for each country's population.

To estimate RTW, we employed a generalized logistic regression model with a binomial link function (proc genmod in SAS 9.3) which can deal with repeated measures. In EU-SILC the same individual may appear up to four times, thus measurements cannot be assumed to be uncorrelated. We also discovered that a few countries had re-used ID numbers as some individuals appeared to have changed birth years. These duplicates were dropped from analyses.

Several correlational structures were tried and the exchangeable (cs) correlation matrix was selected as different structures gave similar results and the exchangeable structure requires the fewest parameters. The material was stratified according to education and predicted values (percentage employed at Year 2) were calculated based on regression estimates. Due to the small sample size, it was not possible to adjust for confounders beyond age and sex in analyses stratified by education. Based on predicted values, rate ratios comparing RTW for low and high/middle educated were calculated for each country.

\section{Policy data}

Relevant policy data are available for 2000-2010, primarily from Eurostat. Data on important conditions such as labour market factors are also readily available from Eurostat. However EPL indicators are only available until 2008 and sickness benefits are available for all countries only from 2008. Therefore, 2008 was chosen as the year 
of measurement. As OECD data is only available for OECD countries, we had to exclude Cyprus, Latvia, Lithuania and Romania from the policy analysis, resulting in 21 cases.

We based our operationalization of flexicurity on the four policy components identified by the European Commission [4]. Our motivation for choosing this particular flexicurity conceptualization is that it is referred to in the European Employment Strategy 2007 and the EU-2020 strategy (Table 2). The particular indicators have been taken from the list proposed by the European Commission [4]. The first EC report [6] also includes the average tax wedge, defined as the difference between the labour cost to the employer and the corresponding net take-home pay of the employee. The inclusion has to

Table 2 Dimensions and indicators of flexicurity

\begin{tabular}{|c|c|c|}
\hline Core dimensions & Operationalization & Indicators \\
\hline $\begin{array}{l}\text { Flexible and reliable } \\
\text { contractual } \\
\text { arrangements }\end{array}$ & $\begin{array}{l}\text { Employment } \\
\text { protection } \\
\text { legislation }\end{array}$ & $\begin{array}{l}\text { EPL (general) } \\
\text { EPT (EPL for temporary } \\
\text { employees) } \\
\text { EPL OR EPT }\end{array}$ \\
\hline $\begin{array}{l}\text { Comprehensive } \\
\text { lifelong learning } \\
\text { strategies }\end{array}$ & Life-long learning & $\begin{array}{l}\text { LLL - Proportion in education } \\
\text { and training during the past } \\
4 \text { weeks }\end{array}$ \\
\hline \multirow[t]{3}{*}{$\begin{array}{l}\text { Effective labour } \\
\text { market policies }\end{array}$} & \multirow[t]{3}{*}{$\begin{array}{l}\text { Active labour } \\
\text { market policy }\end{array}$} & $\begin{array}{l}\text { PES - Expenditure on public } \\
\text { employment services } \\
\text { standardized to the } \\
\text { proportion unemployed }\end{array}$ \\
\hline & & $\begin{array}{l}\text { ALMP - Expenditure on } \\
\text { ALMP measures (training, } \\
\text { job rotation/job sharing, } \\
\text { employment incentives, } \\
\text { supported employment and } \\
\text { rehabilitation, direct job } \\
\text { creation and start-up } \\
\text { incentives) standardized to } \\
\text { the proportion unemployed }\end{array}$ \\
\hline & & $\begin{array}{l}\text { ALMPtot - summary of PES } \\
\text { and ALMP }\end{array}$ \\
\hline \multirow[t]{4}{*}{$\begin{array}{l}\text { Modern social } \\
\text { security systems }\end{array}$} & \multirow[t]{2}{*}{ a. Social security } & $\begin{array}{l}\text { PLMP - Expenditure on } \\
\text { unemployment standardized } \\
\text { to the proportion } \\
\text { unemployed }\end{array}$ \\
\hline & & $\begin{array}{l}\text { Sickben - Expenditure on } \\
\text { sickness benefits standardized } \\
\text { to the proportion with activity } \\
\text { limitations in the age group } \\
45-64 \text { years } \\
\text { PLMP OR Sickben }\end{array}$ \\
\hline & \multirow[t]{2}{*}{ b. Social services } & $\begin{array}{l}\text { ExpChild - Expenditure on } \\
\text { social services directed at } \\
\text { families standardized to the } \\
\text { proportion } 0-4 \text { years }\end{array}$ \\
\hline & & $\begin{array}{l}\text { ExpOld - Expenditure on social } \\
\text { services directed at pensioners } \\
\text { standardized to the } \\
\text { proportion } 65+\text { years } \\
\text { SocExp - summary of } \\
\text { ExpChild and ExpOld }\end{array}$ \\
\hline
\end{tabular}

do with the detrimental effects on unemployment rates of high labour costs, but there is no clear argument why it should be seen as a flexicurity indicator. The second EC report also concerns firm-level practices [7]. As this study deals with 'outsiders', we have not attempted to include such indicators, beyond the LLL indicator.

The success of a particular policy configuration is likely to depend strongly on the current labour market situation, thus we included the employment rate and the unemployment rate as background factors in addition to the policy indicators.

\section{Qualitative comparative analysis}

We used Qualitative Comparative Analysis (QCA) to examine how different combinations of the components of flexicurity were linked to higher RTW or employment chances. QCA was introduced by Charles Ragin [32] and has been used mainly in political science, sociology, economics and management studies, with a particular focus on cross-country comparisons [33]. QCA is a method which, rather than looking for a single causal factor, enables researchers to consider different combinations of conditions ('paths') which lead to the outcome of interest (conjunctural causation). It is case-oriented rather than variable-oriented, and is appropriate for generalizing to a subset of cases, as it recognizes the existence of equifinality (different paths can produce the same outcome) [34].

QCA is an iterative process; it involves first specifying relevant theories and choosing conditions for the analysis, then systematically comparing the cases and qualitatively interpreting the findings in the context of the individual cases. In the previous section we have outlined our hypotheses i.e. the policy components of flexicurity and how research suggests they might impact on RTW for those with activity limitations and low levels of education.

The software produces a 'truth table' showing the data as a list of particular configurations of conditions, where several cases may correspond to a single configuration. In this way cases (countries in our study) are collected into a smaller number of groups which share a common pattern of conditions and outcome. The next step is 'Boolean minimisation' which reduces the long description produced by the truth table to the shortest possible expression. This is what the researcher then examines and interprets 'possibly in terms of causality' (Rihoux et al. [35], p 14). The results of the QCA can be used to identify cases for further comparison and these case studies can in turn deepen our understanding of results.

When first developed, QCA used only dichotomous data i.e. data which could be defined as being either in or out of a set (crisp-set QCA). Subsequently the method was developed to allow multiple characterisation 
of the data and to incorporate 'fuzziness' i.e. allowing for the 'in-ness' or 'out-ness' of the data to be nuanced. Since our indicators were continuous, this version, fuzzy-set QCA, was appropriate [36]. The software used was FsQCA 2.0 [37].

The first step in FsQCA is to calibrate all the conditions and the outcome between 0 (fully outside a set) and 1 (fully in a set). Cases calibrated above 0.5 are more in than out and those below 0.5 are more out than in. The 0.5 threshold (the point of maximum ambiguity) is the most important for the results, as it determines set membership. Ideally, all three thresholds (fully in, fully out, point of maximum ambiguity) should be chosen based on theoretical and empirical arguments, independent of the data. However choosing the 0.5 threshold is often difficult because cases tend to cluster in the middle and theoretical or substantive arguments for choosing any particular point as the division between 'in' and 'out' are weak. (Arguments are often stronger for assigning the 0 and 1 thresholds.) This means that one may want to test multiple thresholds in subsequent analysis [38].

For a full description of how we chose the thresholds for each of our outcomes and conditions see Additional file 1 . Table 3 presents the range of raw indicator scores and the thresholds used. The indicators were calibrated

Table 3 Calibration of conditions and outcomes

\begin{tabular}{|c|c|c|}
\hline & Range & $\begin{array}{l}\text { Thresholds corresponding } \\
\text { to fully in - neither in } \\
\text { nor out - fully out }\end{array}$ \\
\hline \multicolumn{3}{|l|}{ Outcomes } \\
\hline High rate ratio (RR) & $0.38-0.99$ & $0.8-0.66-0.5$ \\
\hline High RTW (\%) & $4-33$ & $35.0-13-9.0$ \\
\hline \multicolumn{3}{|l|}{ Conditions } \\
\hline High Employment (\%) & $61.7-79.0$ & $75.0-71.0-63.0$ \\
\hline Low Unemployment (\%) & $2.8-12.4$ & $5.0-7-9.0$ \\
\hline Low EPL (score 0-6) & $0.74-3.27$ & $1.0-2.0-3.5$ \\
\hline Low EPT (score 0-6) & $0.25-3.83$ & $0.75-1.4-3.5$ \\
\hline High PES ${ }^{a}$ & $0.00-0.11$ & $0.06-0.02-0.007$ \\
\hline High ALMPa & $0.01-0.30$ & $0.25-0.07-0.02$ \\
\hline High ALMPtot (summary score) & $0.01-0.37$ & $0.3-0.07-0.02$ \\
\hline High PLMPa & $0.01-0.46$ & $0.25-0.10-0.02$ \\
\hline High Sickben ${ }^{\text {b }}$ & $0.02-0.24$ & $0.1-0.06-0.035$ \\
\hline High ExpChild ${ }^{c}$ & $0-0.38$ & $0.2-0.1-0.05$ \\
\hline High ExpOld ${ }^{d}$ & $0-0.14$ & $0.1-0.03-0.01$ \\
\hline High SocExp (summary score) & $0.00-0.50$ & $0.3-0.135-0.1$ \\
\hline High LLL (\%) & $2.9-29.9$ & $20-9-5$ \\
\hline
\end{tabular}

${ }^{\mathrm{a}}$ Expenditure as a percentage of GDP per percentage unemployed. ${ }^{\mathrm{b}}$ Expenditure as a percentage of GDP per percentage with activity limitations in the age group 45-64 years. ${ }^{\circ}$ Expenditure on child care as a percentage of GDP per percentage $0-4$ years. ${ }^{\mathrm{d}}$ Expenditure on elder care as a percentage of GDP per percentage 65 and above with the direct method, which uses a logistic function to assign membership scores $0-1$. The full data set with original and calibrated values for all countries is included as Additional file 2.

After calibration, nine countries scored above 0.5 for the outcome 'return to work' and 11 scored above 0.5 for the rate ratio (see Appendix 1, Table 8). There was some overlap as seven out of 13 countries scored highly on both measures.

From the fuzzy-set data, a truth table was constructed (see Table 4), in which each row represents a unique configuration of conditions (and in which 0 equals scores $<0.5$ and 1 equals scores $>0.5$ ). One configuration may represent one or several cases. Through Boolean minimisation, redundant conditions were deleted until no further minimisation was possible and the most parsimonious solutions had been reached. Table 5 provides a simple example of how this process works.

In fuzzy-set QCA, minimization is performed in three different ways according to how 'logical remainders' are used. Logical remainders are combinations of components which are theoretically possible but do not actually exist among the cases. The three ways of minimising are: without logical remainders (most complex); only using logical remainders that do not contradict hypothesized relationships (intermediate) and; using any logical remainder that leads to a more parsimonious solution. Given that real-world data often suffers from a lack of diversity, the first option may not lead to a greatly reduced solution, thus it is often necessary to include logical remainders. We chose the intermediate solution as the main solution; including logical remainders that do not contradict the hypothetical relationship with RTW - presence of high average employment, high ALMP and LLL, high expenditure on social services, and low EPL. Unfortunately fsQCA at present does not allow assumptions regarding combinations of conditions, so flexicurity as a policy package cannot be directly tested. The complex and most parsimonious solutions are found in Additional file 3.

The QCA is performed in two steps, with necessary conditions being analysed separately from sufficient conditions. Necessary conditions are those that are always present when the outcome occurs. For a condition $\mathrm{X}$ to be necessary for $\mathrm{Y}$ to occur, $\mathrm{X}$ should be larger than $\mathrm{Y}$, i.e. it should be a superset of Y. The formula for consistency in fsQCA takes into account not only how many cases are consistent with $\mathrm{X}>\mathrm{Y}$ but also by how much they differ from full consistency. A necessary condition needs by definition to be almost fully consistent, 0.9 or above. Necessary conditions are normally tested one by one, but conditions that could be seen as functionally equivalent for the outcome may also be tested jointly (i.e. joined by the logical OR). 
Table 4 Truth table of included conditions for high RTW (Logical remainders not shown)

\begin{tabular}{|c|c|c|c|c|c|c|c|c|}
\hline Row & Countries & High Emp & Low EPT & High ALMP & High PLMP or Sick & High OldServ & High RTW & Row consistency \\
\hline 1 & NO & 1 & 0 & 1 & 1 & 1 & 1 & 0.86 \\
\hline 2 & UK & 1 & 1 & 0 & 0 & 1 & 1 & 0.84 \\
\hline 3 & $\mathrm{HU}$ & 0 & 0 & 0 & 0 & 1 & 1 & 0.81 \\
\hline 4 & $\mathrm{SE}, \mathrm{FI}, \mathrm{NL}, \mathrm{DK}$ & 1 & 1 & 1 & 1 & 1 & 1 & 0.79 \\
\hline 5 & $\mathrm{EE}, \mathrm{CZ}$ & 1 & 1 & 0 & 0 & 0 & 1 & 0.73 \\
\hline 6 & SK & 0 & 1 & 0 & 0 & 1 & 0 & 0.58 \\
\hline 7 & ES & 0 & 0 & 0 & 1 & 1 & 0 & 0.52 \\
\hline 8 & IE & 0 & 1 & 1 & 1 & 1 & 0 & 0.51 \\
\hline 9 & $P L$ & 0 & 1 & 0 & 0 & 0 & 0 & 0.50 \\
\hline 10 & AT & 1 & 0 & 1 & 1 & 0 & 0 & 0.46 \\
\hline 11 & PT, SI & 1 & 0 & 0 & 1 & 0 & 0 & 0.42 \\
\hline 12 & $G R$ & 0 & 0 & 0 & 0 & 0 & 0 & 0.39 \\
\hline 13 & $\mathrm{FR}, \mathrm{BE}$ & 0 & 0 & 1 & 1 & 0 & 0 & 0.32 \\
\hline 14 & LU, IT & 0 & 0 & 0 & 1 & 0 & 0 & 0.31 \\
\hline
\end{tabular}

Sufficient conditions are those that singly or jointly are enough to produce the outcome, but they represent alternative routes to the outcome, i.e. they are not always present when the outcome is present. This may also be expressed as $\mathrm{X}$ being smaller than $\mathrm{Y}$, i.e. $\mathrm{X}$ is a subset of Y. A common threshold of consistency for sufficiency is 0.8 , but it may be worth testing other thresholds, depending on the empirical reality.

With 21 cases and 13 indicators, plus two background conditions, we found ourselves in a 'too many conditions, too few cases' scenario: five would be the recommended number of conditions for analysing sufficiency for about 20 cases [39]. To reduce the number of conditions, we decided to include as a background indicator alternatively the employment or the unemployment rate, i.e. all models were tested with either one but not both simultaneously. Similarly, we included either EPL or EPT, or both as functionally equivalent. We tested either ALMP or PES, or a summary measure (first summarized, then calibrated, see Additional file 1). We included expenditure for child care and elder care both singly and as a summary measure (first summarized, then calibrated, see Additional file 1). Furthermore, PLMP and sickness benefits were included as functionally equivalent, as we assumed that for this particular group (people with activity limitations due to health problems) either type of social insurance might be used, depending on the system in each country. In this way, five conditions were always included, one of either background indicator, one employment regulation indicator, one of the ALMP/PES indicators, social security benefits, and one social services indicator. Life-long learning is not a clear-cut policy indicator

Table 5 Boolean minimisation - a simple example

\footnotetext{
A truth table with two rows and three conditions (R, B and I) might look like this:

$\mathrm{R}^{*} \mathrm{~B} * \mathrm{I} \longrightarrow \mathrm{O}$

$\mathrm{R}^{*} \mathrm{~B}^{*} \sim \mathrm{I} \longrightarrow \quad \mathrm{O}$

In Boolean algebra, * equals logical AND, while + equals logical OR (i.e. inclusive OR, not either or).

A right-facing arrow equals sufficiency, while a backward-facing arrow equals necessity.

So, in words, the above reads "the simultaneous presence of $\mathrm{R}$ and $\mathrm{B}$ and $\mathrm{I}$ is sufficient for $\mathrm{O}$ " and "the simultaneous presence of R and B and not I is sufficient for O". Thus, the presence or absence $(\sim)$ of $\mathrm{I}$ is redundant and so it can be deleted, leading to the solution term "the simultaneous presence of R and B is sufficient for O". In Boolean algebra, that is written:

$\mathrm{R} * \mathrm{~B} \longrightarrow \mathrm{O}$
}

We have now 'minimised' the equations by getting rid of the redundant term I and so have a more parsimonious solution. 
and probably less important for our target group. It was added to existing promising models.

Different solutions were assessed based on 1) whether there were any contradictory cases i.e. cases covered by the solution term but where the outcome was less than $0.5,2)$ the number of cases covered and, 3) the consistency score for the solution term. Apart from the number of cases covered, each solution also has a coverage score, which is an indication of the empirical weight of a solution term. If cases in the solution have a low membership score (determined by their lowest score on the indicators included in the solution), coverage will also be low.

\section{Results}

How well do countries perform?

Table 1 shows the number included in the analysis for each country, and the total percentage in employment at Year 2. The highest level is found in the Nordic countries (30-39\%) and the lowest in Ireland and Belgium (below $10 \%$ ). Apart from the Nordic countries, some Eastern European and Baltic states, and the UK, also perform quite well (above $20 \%$ ).

Analysis of the EU-SILC data, using the full set of 25 countries, revealed the estimated percentage of those with low education and activity limitations who achieved employment in Year 2. This is shown in Fig. 2 together with the rate ratio i.e. how that compares to those who are more highly educated. There is a high association between the absolute level and the rate ratio $(r=0.76)$. Denmark, Norway and Sweden have the highest prevalence rate of RTW and Norway and Denmark have the highest rate ratio. Latvia performs surprisingly well on both the RTW and RR. Non-OECD countries unfortunately lack data for EPL/EPT, and are therefore excluded from the policy analysis. Due to sometimes low $\mathrm{N}$, estimates are uncertain. It should be noted in particular that cell counts below 10 are found in Ireland and Slovakia. Cell counts between 10 and 20 are found in Lithuania, Belgium, Denmark, Greece, Romania, and Sweden. This means that estimates should be seen as proximate, and that the particularly high scores for Denmark and Sweden are uncertain.

\section{QCA analyses}

Outcome 1: High rates of return to work among those with low education

For RTW, the only necessary condition was high average employment, with a consistency of 0.92 . One case (Hungary) was highly deviant, with a very low employment rate and an RTW just above 0.5 (see Fig. 3). Also the Czech Republic falls slightly above the line, with lower membership in high employment (0.56) than it has in the outcome (0.66). Since high employment was necessary, it was retained in all analyses, and low unemployment was not tested in analyses of sufficiency.

After Boolean minimisation, and assessment of different solutions according to the steps described on page $\mathrm{x}$, the QCA solution chosen consisted of the following five conditions: high average employment, low EPT, high ALMP, high expenditure on social services in old age and high PLMP OR sickness benefit. The truth table for those conditions shows that only 14 out of the $32\left(2^{5}\right)$ possible combinations were found to exist within the given set of countries (Table 4). Given these five conditions there are three combinations or paths, which cover all countries above the 0.5 threshold. In order to include the two cases in the fifth row (the Czech

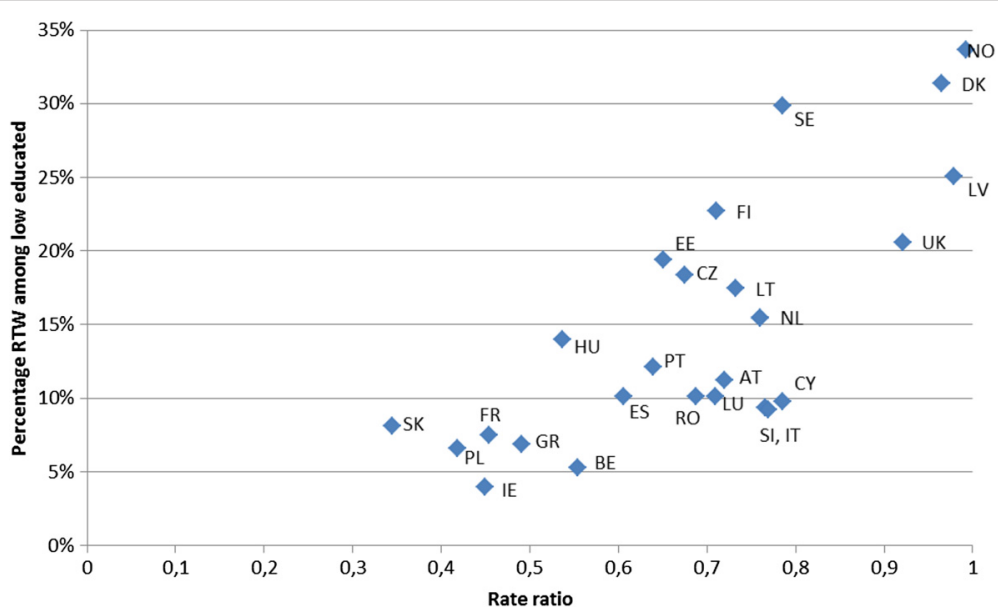

Fig. 2 Percentage in employment after one year among those with low education and activity limitations, and the rate ratio comparing low and middle/high educated 


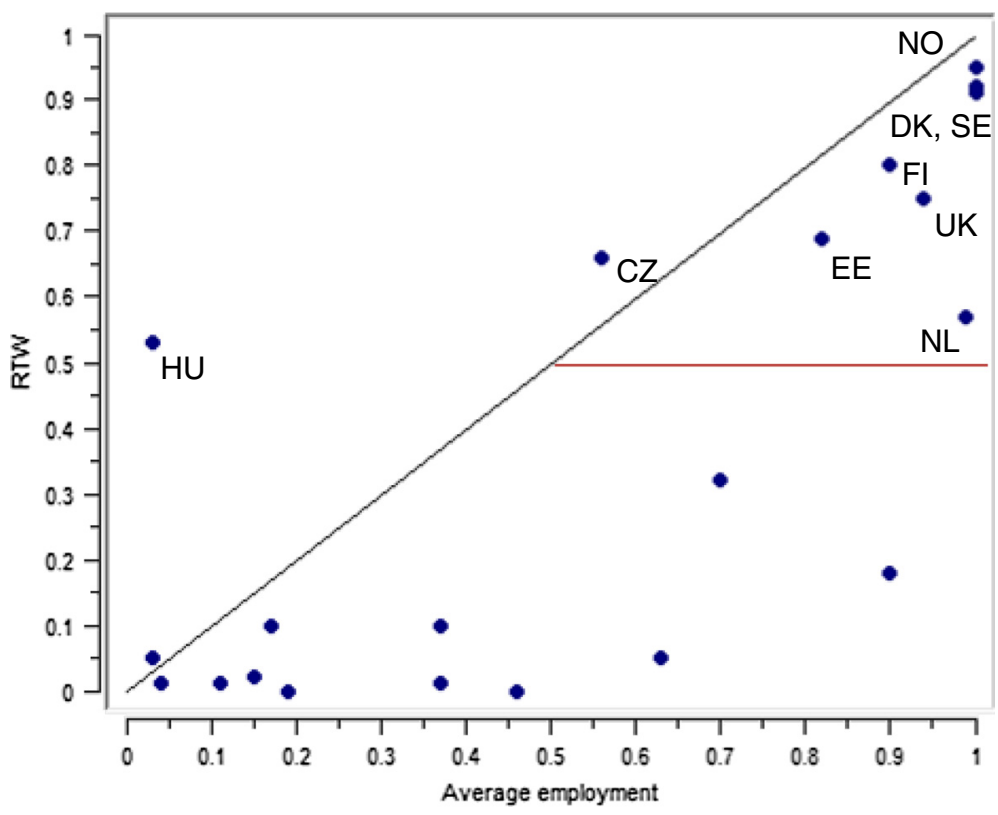

Fig. 3 Scatter plot of average employment and RTW (calibrated scores). Countries included in QCA indicated

Republic and Estonia), we decided on a lenient consistency threshold (0.7).

The intermediate solution has the following three paths:

\section{Emp*OldServ*ALMP}

Denmark $(0.97,0.92)$, Norway $(0.91,0.95)$, the

Netherlands $(0.78,0.57)$, Sweden $(0.69,0.91)$,

Finland $(0.69,0.80)$

2. EmP*EPT * PLMP_Sick

the UK $(0.80,0.75)$, Estonia $(0.57,0.69)$, The Czech Republic $(0.56,0.66)$

3. OldServ* $\sim$ EPT * $\sim$ PLMP_Sick

Hungary $(0.51,0.53)$

The overall solution consistency is 0.78 . Solution coverage is 0.91 . It should be noted that solutions with EPL instead of EPT excluded the borderline case Hungary. Using PES instead of ALMP, or including LLL also led to lower coverage. The figures in brackets after each country represent its row membership and outcome scores. For example, Sweden and Finland have the lowest row membership in path $1(0.69)$. This is because of their relatively low score on ALMP. Norway is the most typical case in this path, with the highest membership and outcome scores.

The paths are illustrated using scatter plots (Figs. 4 and 5) which plot set membership against RTW outcomes. The first path encompasses the Nordic countries and the Netherlands. These are distinguished by their high employment rates and high expenditure on ALMP, combined with high expenditure on services directed at the elderly. Social service expenditure directed at families was also tested, but this solution covered fewer countries, and included a contradictory case (Austria). The fact that elder care is more important could well be explained by the age profile of the target group, where $41 \%$ are 50 or above; caring for elderly parents as an exit route is more relevant than caring for children. In Fig. 4 we can see that the Netherlands performs poorly compared to its policy neighbours, despite scoring near 1 on both ALMP and employment. The Netherlands

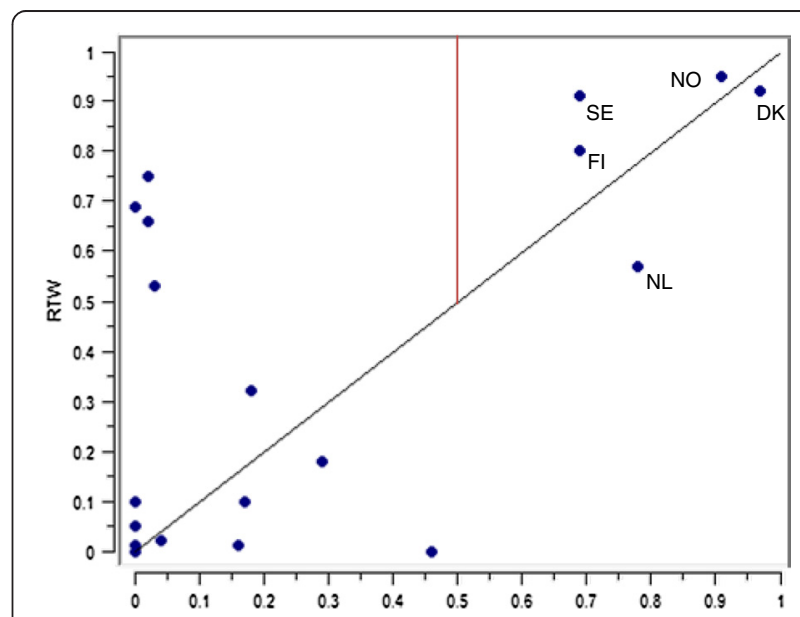

Fig. 4 Scatter plot of membership scores for path 1 and RTW (calibrated scores). Included countries indicated 


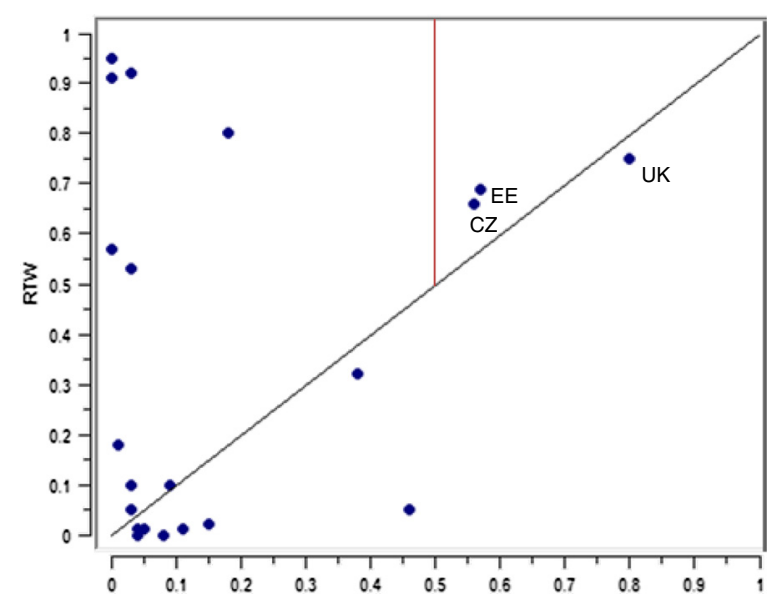

Fig. 5 Scatter plot of membership scores for path 2 and RTW (calibrated scores). Included countries indicated

is thus a contradictory case, although just by degree as it still falls above the 0.5 threshold for the outcome [40]. It does however have the lowest expenditure on social services (in old age and overall) of the five cases, and its female employment rate lags behind males by 13.5 percentage points (compared to 4-8 percentage points for the Nordic countries). Also, policies for people with activity limitations focus especially on 'insiders', i.e. those already in employment, placing strict obligations on employers that may act as a disincentive to employing people with known health conditions [41].

The countries in Fig. 5 are distinguished by having high employment rates, low regulation of employment (temporary and overall), and low levels of social security benefits. However, scores vary quite substantially, with the UK and the Czech Republic having very low regulation and Estonia scoring just below the 0.5 threshold, and the Czech Republic falling just over the threshold for high employment. They all have very low expenditure on both sickness and unemployment benefits. Figure 5 shows that the UK falls just below the diagonal, due to the fact that their RTW score is lower than their membership score. They do however perform slightly better than the others.

The third path represents the outlier Hungary. Hungary is a borderline case, both regarding the outcome (0.53) and its membership score (0.51), due its relatively low old age expenditure. Hungary is a puzzling case, as it has about the same RTW as the Netherlands, despite having low employment rates for both men and women. The path arrived at in the solution may not give us much in the way of an explanation, and Hungary is a suitable case for indepth analysis.

\section{Outcome 2: High equality of employment chances (rate ratio)}

Again, we start with the analysis of necessary conditions. For the rate ratio, no condition scores above the 0.9 threshold of consistency. However, some come close, especially employment (0.87) and unemployment (0.86). With this in mind, we proceed to the analysis of sufficiency.

The best solution covers all countries with the outcome and consisted of the following five conditions: low average unemployment, low EPL, high ALMP, high expenditure on social services and high PLMP OR sickness benefit. When employment rather than unemployment is used, the solution covers contradictory cases. Including either PES or LLL also leads to contradictory cases. Using either EPL or EPT gives the same result, although the consistency score is slightly higher with EPL. The truth table for the chosen conditions consists of only 11 rows, out of 32 possible combinations (Table 6).

Table 6 Truth table of included conditions for high RR (Logical remainders not shown)

\begin{tabular}{lllllllll}
\hline Row & Countries & Une-ave & Low EPL & ALMP & SocExp & PLMP or Sickben & RR & Row consistency \\
\hline 1 & SE, FI, NL, DK & 1 & 1 & 1 & 1 & 1 & 1 & 0.98 \\
2 & NO, AT & 1 & 0 & 1 & 1 & 1 & 1 & 0.97 \\
3 & UK, CZ & 1 & 1 & 0 & 0 & 0 & 1 & 0.94 \\
4 & SI, IT, LU & 1 & 0 & 0 & 0 & 1 & 1 & 0.92 \\
5 & FR & 0 & 0 & 1 & 1 & 1 & 0 & 0.76 \\
6 & HU & 0 & 1 & 0 & 1 & 0 & 0 & 0.68 \\
7 & ES & 0 & 0 & 0 & 1 & 1 & 0.66 & 0.65 \\
8 & PT & 0 & 0 & 0 & 0 & 0 & 0 & 0.59 \\
9 & GR & 0 & 0 & 0 & 0 & 0 & 0 & 0.48 \\
10 & EE, PL, SK & 0 & 1 & 0 & 0 & 0 & 0.44 \\
\hline
\end{tabular}


Given these five conditions there are two somewhat overlapping paths, with only two conditions in the intermediate solution:

1. Uneave * PLMP_Sick

Norway $(1,1)$, the Netherlands (1, 0.9), Austria

(0.97, 0.78), Denmark $(0.97,1)$, Sweden $(0.73,0.94)$,

Luxembourg (0.62, 0.74), Finland $(0.54,0.75)$,

Slovenia $(0.53,0.91)$, Italy $(0.52,0.91)$

2. Uneave "EPL

UK $(0.94,1)$, Denmark $(0.86,1)$, the Netherlands

$(0.68,0.9)$, Sweden $(0.64,0.94)$, Czech Republic

$(0.63,0.58)$, Finland $(0.51,0.75)$

The countries that are present in both paths are the Netherlands, Denmark, Sweden and Finland.

As Fig. 6 shows, Denmark and Norway are the foremost example of the first set of countries, distinguished by low unemployment and high benefit expenditure. The Netherlands and Austria fall slightly below the diagonal, especially Austria, which has a membership score of almost 1, but an outcome score just below 0.8. As is evident here, it seems that adequate benefit levels can comfortably co-exist with equality of RTW, at least in low unemployment contexts.

The countries in path 2, of which the UK is the foremost example, have low unemployment rates and low regulation of employment protection. However, the UK and the Czech Republic are the sole countries present only in this path. Compared to the remaining countries, they both have low benefit levels. However, benefit levels is not a component in the solution. Thus low EPL/EPT is advantageous to the equality of RTW regardless of benefit levels, and there is no trade-off between flexibility and security (Fig. 7).

\section{Discussion}

The purpose of this study was to investigate the impact of flexicurity policies across Europe on the return to work and social differentials in return to work for people with activity limitations.

For the absolute level of return to work among people with low education and activity limitations, the QCA revealed that apart from high employment rates, either flexibility (ALMP and social services in old age), or flexibility in combination with insecurity (low employment regulation and low benefit levels), led to high levels of RTW among people with activity limitations and low education.

These two routes can be viewed as the high road and the low road, or carrot vs stick. In the first path, high employment rates and ALMPs help people access new jobs, while social services in old age may be seen as a precondition for high employment rates in this particular group (and with the public sector as a major employer). In the second path, relatively high employment rates and low employment protection (both EPL and EPT) creates an opportunity to re-enter the labour market, while the very low income protection creates a strong incentive. However, while the low road is cheaper, it is also less effective, producing on average $19 \%$ RTW compared to $27 \%$.

There were various ways the discovery of the 'contradictory' borderline case of Hungary could

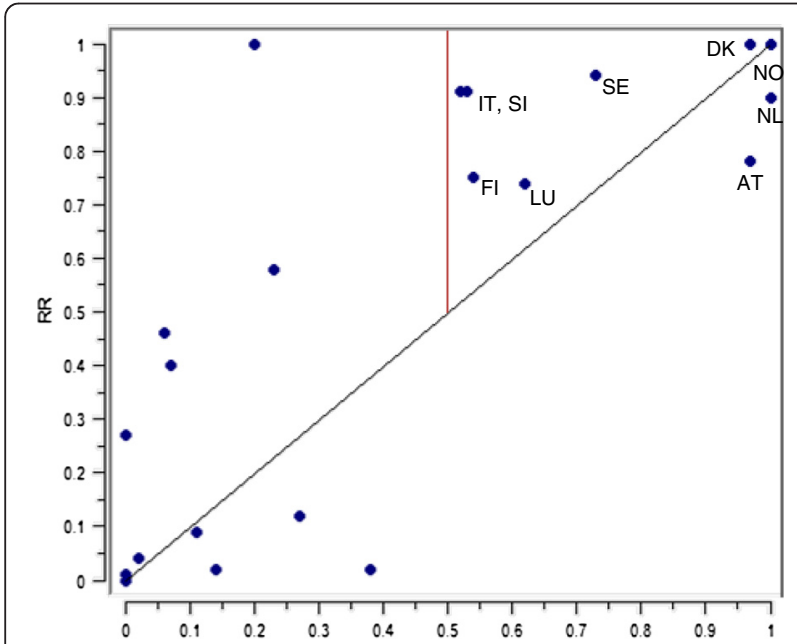

Fig. 6 Scatter plot of membership scores for path 1 and RR (calibrated scores). Included countries indicated

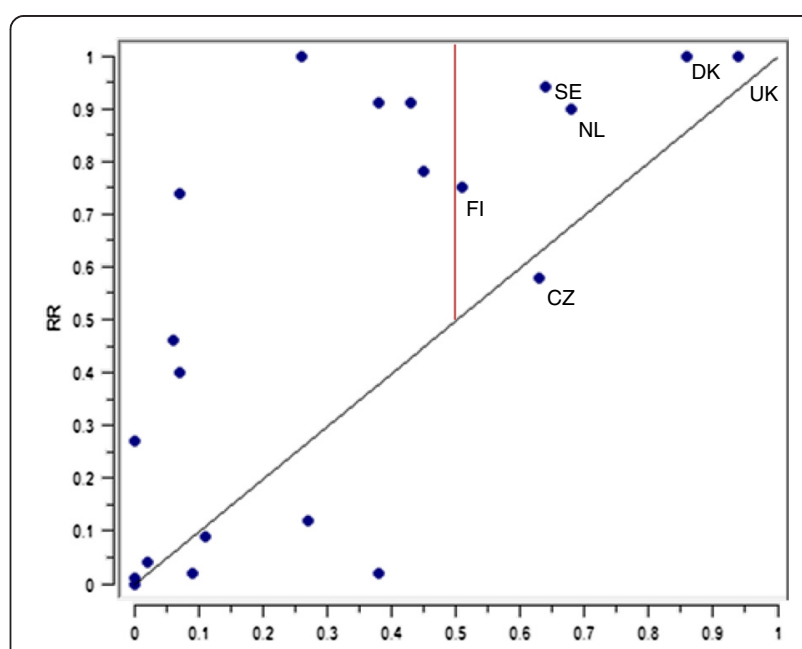

Fig. 7 Scatter plot of included countries' membership score for path 2 and RR (calibrated scores). Included countries indicated 
have been handled. It could have been disregarded due to failing the otherwise necessary condition of high employment rates. The threshold for RTW could have been tweaked. However, uncovering the existence of such deviant or contradictory cases can be regarded as a strength of QCA if it prompts "dialogue with the data" [35] p 15) i.e. encourages further study of the case in question. Solutions with EPL instead of EPT excluded Hungary. Unlike for temporary employment, Hungary has a low level of overall employment regulation, and thus is similar to the countries in solution 2, except for its employment rate. However, when low EPL is included it shares a row with Slovakia, which has a very low RTW (calibrated value of 0.02 , absolute value $8 \%$ ). This row has a consistency score of 0.59 and is not included in the minimization process. Given Hungary's unfavourable combination of conditions; high regulation of temporary employment, low benefit expenditure and (relatively) high old age expenditure, in a low employment/high unemployment context, a more in-depth study of the Hungarian situation is required in order to understand its relatively high level of RTW.

As shown, differences in RTW based on education are substantial in many countries, but negligible in others. The QCA suggests that either flexibility (low EPL) or security (high benefit expenditure), in conjunction with low unemployment, is sufficient to produce equality of RTW. Thus no solution for either RTW or RR combines aspects of both flexibility and security, which calls into question whether flexicurity as a policy package is of importance for the target group. However, as the complex solutions show (see Additional file 3), in the real world the two dimensions co-exist in the top scoring countries. The problem of limited diversity is common and not easily overcome. Relatively high AND equal RTW is only found in three countries (Norway, Denmark and Sweden) and these are characterized by both flexibility and security. It should be noted that the strictness of employment regulation differs widely between these three.

However, as previously noted, the subgroup with both low education and activity limitations is small in certain countries, making estimates uncertain. This is especially the case for Sweden and Denmark among the high performing countries. As for any survey, there is always a problem with biased non-response, and response rates also differ markedly between countries [42]. As the time period 2005-2010 includes the worst years of the recession it is likely that RTW is lower than in previous periods, and a similar study conducted today might well come to a different conclusion.
Throughout this paper and its appendices, we have tried to be transparent about the inevitable choices and judgements the practice of QCA requires especially concerning the crucial threshold between 'more in than out' and 'more out than in'. Through such transparency we hope to contribute to methodological progress, opening our work up to Campbell's "disputatious community of truth seekers" [43] p 513). In this way, studies such as ours can not only be repeated but also refined - subsequent research can "modify the operationalization of the variables for further tests, include other variables, aggregate some proximate variables, etc." [35] p 17).

If people with low education are especially badly hit when experiencing health problems, this may be an important mechanism in explaining health inequalities $[1,3]$. As stated by the WHO, chronic diseases and poverty are interconnected in a vicious cycle, and even in countries with well-developed social security systems, people with chronic diseases and disabilities still experience adverse economic consequences (http:// www.who.int/chp/chronic_disease_report/part2_ch2/en/). Being able to remain in the labour market is thus likely to be crucial for the individual's opportunities for health.

A related topic which we have not addressed here is the type of employment - subsidized or regular and the quality of employment found. If workers with activity limitations are primarily allocated to more precarious employment (i.e. temporary, lowwage, and nonunion jobs), it is less likely that their needs for work place adjustment will be met [44]. This in turn may mean that the risk of future job loss remains high. It is the combination of inflow and outflow that determines the overall employment rate of this group, thus differences between the outcomes of this study and the overall employment rates are to be expected.

\section{Conclusion}

We found two routes that lead to high RTW: we characterise these as the high road and the low road. Some countries seem to do everything right, but at a considerable cost, made possible by the high overall employment rate. Taking the low road (relaxing employment protection and limiting benefits) may be a tempting option for poorly performing countries. However, without measures to stimulate female employment it may not be sufficient as high overall employment is so important in enabling people with activity limitations to access the labour market. To achieve equality in RTW, it seems that as long as unemployment is low, either flexibility or security is adequate. 


\section{Appendix 1}

Table 7 Educational distribution and percentage with low educational attainment

\begin{tabular}{|c|c|c|c|c|c|c|c|c|}
\hline ISCED & None or pre-primary & Primary & Lower secondary & Upper secondary & Post-secondary non-tertiary & Tertiary & Low education & $\mathrm{N}$ \\
\hline AT & 0.4 & 5 & 36 & 46 & 5 & 7 & 21 & 690 \\
\hline $\mathrm{BE}$ & 13 & 18 & 27 & 30 & 1 & 10 & 31 & 871 \\
\hline CY & 6 & 46 & 12 & 23 & 4 & 9 & 52 & 593 \\
\hline$C Z$ & 0 & 0 & 26 & 69 & 0.4 & 5 & 26 & 706 \\
\hline DK & 0 & 0 & 25 & 36 & 0 & 39 & 25 & 202 \\
\hline $\mathrm{EE}$ & 0.2 & 1 & 24 & 56 & 8 & 12 & 25 & 623 \\
\hline ES & 7 & 39 & 30 & 15 & 0.6 & 9 & 46 & 2345 \\
\hline $\mathrm{Fl}$ & 0 & 2 & 20 & 55 & 0 & 22 & 22 & 457 \\
\hline FR & 7 & 21 & 25 & 37 & 0 & 11 & 28 & 1298 \\
\hline GR & 4 & 51 & 15 & 22 & 3 & 5 & 55 & 532 \\
\hline $\mathrm{HU}$ & 1 & 9 & 34 & 50 & 1 & 4 & 44 & 1138 \\
\hline $\mathrm{IE}$ & 2 & 41 & 27 & 16 & 5 & 8 & 43 & 516 \\
\hline IT & 11 & 23 & 38 & 22 & 3 & 3 & 34 & 2238 \\
\hline LT & 0 & 1 & 15 & 44 & 32 & 8 & 16 & 437 \\
\hline LU & 2 & 48 & 15 & 25 & 1 & 10 & 50 & 632 \\
\hline LV & 1 & 4 & 22 & 60 & 8 & 7 & 27 & 810 \\
\hline $\mathrm{NL}$ & 0.6 & 12 & 29 & 37 & 3 & 19 & 41 & 660 \\
\hline $\mathrm{NO}$ & 0 & 0.5 & 26 & 48 & 4 & 22 & 27 & 191 \\
\hline$P L$ & 2 & 28 & 0 & 64 & 3 & 4 & 30 & 1512 \\
\hline PT & 13 & 71 & 8 & 6 & 0.2 & 2 & 84 & 1144 \\
\hline $\mathrm{RO}$ & 0 & 13 & 49 & 35 & 1 & 1 & 62 & 231 \\
\hline SE & 0 & 9 & 11 & 48 & 8 & 25 & 20 & 208 \\
\hline SI & 2 & 16 & 23 & 54 & 0.5 & 4 & 23 & 583 \\
\hline SK & 0 & 0.9 & 18 & 75 & 0.2 & 5 & 19 & 446 \\
\hline UK & 0 & 0 & 30 & 47 & 4 & 19 & 30 & 676 \\
\hline
\end{tabular}

Table 8 Calibrated scores for countries high on RTW or RR (or both) - original and calibrated values for all countries are included as an Additional file 2

\begin{tabular}{|c|c|c|c|c|c|c|c|c|c|c|c|c|c|c|}
\hline Country & $\begin{array}{l}\text { High } \\
\text { Emp }\end{array}$ & $\begin{array}{l}\text { Low } \\
\text { Unemp }\end{array}$ & $\begin{array}{l}\text { Low } \\
\text { EPL }\end{array}$ & $\begin{array}{l}\text { Low } \\
\text { EPT }\end{array}$ & $\begin{array}{l}\text { High } \\
\text { ALMP }\end{array}$ & $\begin{array}{l}\text { High } \\
\text { PES }\end{array}$ & $\begin{array}{l}\text { High } \\
\text { ALMP tot }\end{array}$ & $\begin{array}{l}\text { High } \\
\text { LLL }\end{array}$ & $\begin{array}{l}\text { High } \\
\text { SocExp }\end{array}$ & $\begin{array}{l}\text { High } \\
\text { Childexp }\end{array}$ & $\begin{array}{l}\text { High } \\
\text { OldExp }\end{array}$ & $\begin{array}{l}\text { High PLMP } \\
\text { OR Sickben }\end{array}$ & $\begin{array}{l}\text { High } \\
\text { RTW }\end{array}$ & $\begin{array}{l}\text { High } \\
\text { RR }\end{array}$ \\
\hline Norway & 1 & 1 & 0.26 & 0.17 & 0.91 & 0.84 & 0.86 & 0.94 & 0.98 & 0.98 & 0.98 & 1 & 0.95 & 1 \\
\hline Denmark & 1 & 0.98 & 0.86 & 0.57 & 0.99 & 0.98 & 0.98 & 1 & 1 & 1 & 0.97 & 0.97 & 0.92 & 1 \\
\hline Sweden & 1 & 0.73 & 0.64 & 0.96 & 0.69 & 0.86 & 0.74 & 0.97 & 0.99 & 0.99 & 0.99 & 1 & 0.91 & 0.94 \\
\hline Finland & 0.9 & 0.54 & 0.51 & 0.57 & 0.69 & 0.24 & 0.67 & 0.98 & 0.97 & 0.99 & 0.8 & 0.82 & 0.80 & 0.75 \\
\hline UK & 0.94 & 0.94 & 0.98 & 0.99 & 0.02 & 0.89 & 0.27 & 0.95 & 0.23 & 0.32 & 0.55 & 0.2 & 0.75 & 1 \\
\hline Estonia & 0.82 & 0.06 & 0.56 & 0.57 & 0.02 & 0.04 & 0.01 & 0.55 & 0 & 0.01 & 0 & 0.09 & 0.69 & 0.46 \\
\hline $\begin{array}{l}\text { Czech } \\
\text { Republic }\end{array}$ & 0.56 & 0.75 & 0.63 & 0.94 & 0.11 & 0.56 & 0.37 & 0.29 & 0 & 0.02 & 0.02 & 0.23 & 0.66 & 0.58 \\
\hline Netherlands & 0.99 & 1 & 0.68 & 0.94 & 0.99 & 1 & 0.98 & 0.9 & 0.51 & 0.22 & 0.78 & 1 & 0.57 & 0.90 \\
\hline Hungary & 0.03 & 0.11 & 0.62 & 0.38 & 0.06 & 0.09 & 0.07 & 0.01 & 0.57 & 0.65 & 0.51 & 0.12 & 0.53 & 0.09 \\
\hline Slovenia & 0.73 & 0.86 & 0.38 & 0.46 & 0.05 & 0.27 & 0.10 & 0.79 & 0.12 & 0.56 & 0 & 0.53 & 0.05 & 0.91 \\
\hline Italy & 0.03 & 0.52 & 0.43 & 0.23 & 0.30 & 0.04 & 0.36 & 0.12 & 0.39 & 0.67 & 0 & 0.55 & 0.05 & 0.91 \\
\hline Luxembourg & 0.46 & 0.98 & 0.07 & 0.03 & 0.44 & 0.06 & 0.52 & 0.41 & 0.23 & 0.65 & 0 & 0.62 & 0.10 & 0.74 \\
\hline Austria & 0.92 & 0.97 & 0.45 & 0.38 & 0.82 & 0.82 & 0.80 & 0.76 & 0.52 & 0.60 & 0.29 & 0.99 & 0.18 & 0.78 \\
\hline
\end{tabular}




\section{Additional files}

Additional file 1: Calibration of conditions. (DOCX $27 \mathrm{~kb}$ )

Additional file 2: QCA data set. Original and calibrated scores. (CSV $3 \mathrm{~kb}$ )

Additional file 3: Most complex and most parsimonious solution. (DOCX $14 \mathrm{~kb}$ )

\section{Funding}

This research was funded by the European Commission as part of the Demetriq-project (Contract/Grant agreement number 278511).

\section{Availability of data and materials}

The data used for the QCA can be found in Additional file 3. Eurostat microdata is confidential and cannot be accessed by non-authorised persons or parties according to the terms of the confidentiality declaration.

\section{Authors' contributions}

MCB performed all QCA analyses, participated in analyzing EU-silc data, and prepared the main manuscript. SM contributed with text to the manuscript and participated in methodological discussions. DB participated as a statistical consultant and performed analyses on EU-silc data. MW critically appraised the manuscript and participated in study design. BB participated in study design, took part in all discussions and critically appraised the manuscript. All authors read and approved the final manuscript.

\section{Competing interests}

The authors declare that they have no competing interests.

\section{Consent for publication}

Not applicable.

\section{Ethics approval and consent to participate}

This study was approved by the Stockholm Regional Ethical Review Board (2010/2052-31/5). The EU-silc data was collected with informed consent.

\section{Author details}

${ }^{1}$ Department of Public Health Sciences, Karolinska Institutet, Stockholm, Sweden. ${ }^{2}$ Centre for Epidemiology and Community Health, Stockholm County Council, Stockholm, Sweden. ${ }^{3}$ Division of Health Research, Lancaste University, Lancaster, UK. ${ }^{4}$ Public Health and Policy, University of Liverpool, Liverpool, UK.

Received: 19 September 2015 Accepted: 11 August 2016

Published online: 19 August 2016

\section{References}

1. Dray-Spira R. Chronic diseases and employment: Impact on social health inequalities. Revue D Epidemiologie Et De Sante Publique. 2013;61:S146-51. doi:10.1016/j.respe.2013.04.002

2. Holland P, Nylen L, Thielen K, van der Wel KA, Chen WH, Barr B, et al. How do macro-level contexts and policies affect the employment chances of chronically ill and disabled people? PART II: The impact of active and passive labor market policies. Int J Health Serv. 2011;41(3):415-30. doi:10.2190/HS.41.3.b.

3. Clayton S, Barr B, Nylen L, Burstrom B, Thielen K, Diderichsen F, et al. Effectiveness of return-to-work interventions for disabled people: systematic review of government initiatives focused on changing the behaviour of employers. Eur J Public Health. 2012;22(3):434-9. doi:10.1093/ eurpub/ckr101.

4. European Commission. Towards Common Principles of Flexicurity: More and better jobs through flexibility and security. Luxembourg: Office for Official Publications of the European Communities; 2007

5. Sperber S. What are the ingredients of "good" flexicurity arrangements? Some ideas for identifying factors that make for success. Reconciling labour flexibility with social cohesion - Facing the challenge. Trends in social cohesion, No. 15. Strasbourg, Belgium: Council of Europe Publishing; 2005.

6. European Commission. Flexibility and security in the EU labour markets. In: Directorate-General for Employment SAaEOUD, editor. Employment in
Europe. Luxembourg: Office for Official Publications of the European Communities; 2006.

7. European Commission. Working time, work organisation and internal flexibility - flexicurity models in the EU. In: Directorate-General for Employment SAaEOUD, editor. Employment in Europe. Luxembourg: Office for Official Publications of the European Communities; 2007.

8. European Foundation for the Improvement of Living and Working Conditions. Approaches to flexicurity: EU models. Luxembourg: Office for Official Publications of the European Communities; 2007.

9. Nardo M, Rossetti F. Flexicurity in Europe. Administrative Agreement JRC N ${ }^{\circ}$ 31962-2010-11 NFP ISP - FLEXICURITY 2: European Union; 2013.

10. Laporsek S, Dolenc P. Do Flexicurity Policies Affect Labour Market Outcomes? An Analysis of EU Countries. Revija Za Socijalnu Politiku. 2012; 19(2):107-30. doi:10.3935/rsp.v19i2.1018.

11. Rihoux B, Ragin CC. Configurational Comparative methods. Applied social research methods series. Thousand Oaks, CA: Sage; 2009.

12. Lee SSY. Examining policy configurations as conditions for long-term unemployment and non-standard employment in OECD countries using fuzzy-set analysis. Qual Quant. 2013;47(6):3521-36. doi:10.1007/s11135012-9737-9

13. van der Wel KA, Dahl E, Thielen K. Social inequalities in 'sickness': European welfare states and non-employment among the chronically ill. Soc Sci Med. 2011;73(11):1608-17. doi:10.1016/j.socscimed.2011.09.012.

14. de Lange M, Gesthuizen M, Wolbers MHJ. Youth Labour Market Integration Across Europe The impact of cyclical, structural, and institutional characteristics. Eur Soc. 2014;16(2):194-212. doi:10.1080/14616696.2013.821621.

15. Millan A, Millan JM, Roman C, van Stel A. How does employment protection legislation influence hiring and firing decisions by the smallest firms? Econ Lett. 2013;121(3):444-8. doi:10.1016/j.econlet.2013.09.021.

16. Reeves A, Karanikolos M, Mackenbach J, McKee M, Stuckler D. Do Employment Protection Policies Reduce the Relative Disadvantage in the Labour Market experienced by Unhealthy People? A natural experiment created by the Great Recession in Europe.

17. Leonardi M, Pica G. Who pays for it? The heterogeneous wage effects of employment protection legislation. Econ J. 2013;123(573):1236-78. doi:10.1111/ecoj.12022

18. Picchio $M$, van Ours JC. Retaining through training even for older workers. Econ Educ Rev. 2013;32:29-48. doi:10.1016/j.econedurev.2012.08.004.

19. Booth AL, Bryan ML. Testing some predictions of human capital theory: New training evidence from Britain. Rev Econ Stat. 2005:87(2):391-4. doi:10.1162/0034653053970357.

20. Card D, Kluve J, Weber A. Active Labour Market Policy Evaluations: A MetaAnalysis. Econ J. 2010;120(548):F452-77. doi:10.1111/j.1468-0297.2010.02387.x.

21. Kluve J. The effectiveness of European active labor market programs. Labour Econ. 2010;17(6):904-18. doi:10.1016/j.labeco.2010.02.004

22. Osikominu A. Quick Job Entry or Long-Term Human Capital Development? The Dynamic Effects of Alternative Training Schemes. Rev Econ Stud. 2013; 80(1):313-42. doi:10.1093/restud/rds022.

23. Rinne U, Schneider M, Uhlendorff A. Do the skilled and prime-aged unemployed benefit more from training? Effect heterogeneity of public training programmes in Germany. Appl Econ. 2011;43(25):3465-94. doi:10.1080/00036841003670697.

24. Tatsiramos K, van Ours JC. Labor market effects of unemployment insurance design. J Econ Surv. 2014;28(2):284-311. doi:10.1111/joes.12005.

25. van der Klaauw B, Van Ours JC. Carrot and stick: How re-employment bonuses and benefit sanctions affect exit rates from welfare. J Appl Econ. 2013;28(2):275-96. doi:10.1002/jae.1265

26. Arni $P$, Lalive $R$, Van Ours JC. How effective are unemployment benefit sanctions? Looking beyond unemployment exit. J Appl Econ. 2013;28(7): 1153-78. doi:10.1002/jae.2289.

27. Fevang E, Markussen S, Roed K. The Sick Pay Trap. J Labor Econ. 2014;32(2): 305-36. doi:10.1086/673400.

28. Ziebarth NR, Karlsson M. A natural experiment on sick pay cuts, sickness absence, and labor costs. J Public Econ. 2010:94(11-12):1108-22. doi:10.1016/j.jpubeco.2010.09.001

29. Ziebarth NR. Long-term absenteeism and moral hazard-Evidence from a natural experiment. Labour Econ. 2013;24:277-92. doi:10.1016/j.labeco. 2013.09.004

30. Haan P, Wrohlich K. Can child care policy encourage employment and fertility? Evidence from a structural model. Labour Econ. 2011;18(4):498-512. doi:10.1016/j.labeco.2010.12.008. 
31. Burström B, Holland P, Diderichsen F, Whitehead M. Winners and losers in flexible labor markets: the fate of women with chronic illness in contrasting policy environments - Sweden and Britain. Int J Health Serv. 2003;33(2):199-217.

32. Ragin CC. The comparative method. Moving beyond qualitative and quantitative strategies. Berkeley: University of California Press; 1987.

33. Rihoux B, Alamos-Concha P, Bol D, Marx A, Rezsohazy I. From Niche to Mainstream Method? A Comprehensive Mapping of QCA Applications in Journal Articles from 1984 to 2011. Political Research Quarterly. 2013;66(1): 175-84. doi:10.1177/1065912912468269c.

34. Schneider CQ, Wagemann C. Introduction. Set-teoretic methods for the social sciences. A guide to qualitative comparative analysis. Cambridge: Cambridge University Press; 2012. p. 1-20.

35. Rihoux B, Rezsöhazy I, Bol D. Qualitative Comparative Analysis (QCA) in public policy analysis: an extensive review. German Policy Studies. 2011;7(3):9-82.

36. Ragin CC. Qualitative Comparative Analysis Using Fuzzy Sets (fSQCA). In: Rihoux B, Ragin CC, editors. Configurational Comparative Analysis. Thousand Oaks, CA and London: Sage Publications; 2008. p. 87-121.

37. Ragin CC, Drass KA, Davey S. Fuzzy-Set/Qualitative Comparative Analysis. 2.0 ed. Tucson, Arizona: Department of Sociology, University of Arizona; 2006.

38. Skaaning SE. Assessing the Robustness of Crisp-set and Fuzzy-set QCA Results. Sociol Methods Res. 2011;40(2):391-408. doi:10.1177/0049124111404818.

39. Marx A, Dusa A. Crisp-Set Qualitative Comparative Analysis (csQCA), Contradictions and Consistency Benchmarks for Model Specification. Methodological Innovations Online. 2011;6(2):103-48.

40. Schneider C, Rohlfing I. Combining QCA and process tracing in set-theoretic multi-method research. Sociol Methods Res. 2013:42(4):559-97.

41. Hogelund J. In Search of Effective Disability Policy. Comparing the Developments and Outcomes of Dutch and Danish Disability Policies. Amsterdam: Amsterdam University Press; 2003.

42. Goedeme T. How much confidence can we have in EU-silc? Complex sample designs and the standard error of the Europe 2020 poverty indicators. Soc Indices Res. 2013;110:89-110. doi:10.1007/s11205-011-9918-2.

43. Campbell D. Methodology and Epistemology for Social Science: Collected papers. Chicago: University of Chicago Press; 1988.

44. Shuey KM, Jovic E. Disability Accommodation in Nonstandard and Precarious Employment Arrangements. Work Occup. 2013;40(2):174-205. doi:10.1177/0730888413481030

\section{Submit your next manuscript to BioMed Central and we will help you at every step:}

- We accept pre-submission inquiries

- Our selector tool helps you to find the most relevant journal

- We provide round the clock customer support

- Convenient online submission

- Thorough peer review

- Inclusion in PubMed and all major indexing services

- Maximum visibility for your research

Submit your manuscript at www.biomedcentral.com/submit

C Biomed Central 